
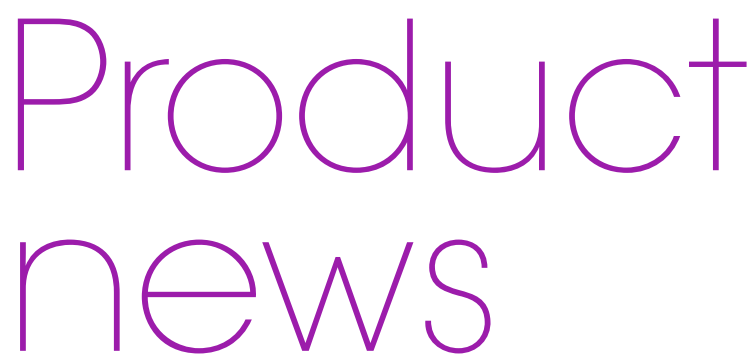

\title{
SUSTAINABLE PRODUCTS TO REDUCE PLASTIC WASTE
}

Independent dental handpiece experts Trigiene Dental has announced the launch of its reusable Eco Repair Box and a new eco range of sustainable products which aim to greatly reduce the sector's heavy reliance on single-use plastic.

The dental sector traditionally uses equipment which is sterilised and often wrapped in plastic alongside numerous single-use items including face masks, gloves and cups.

Middlesbrough-based company Trigiene Dental is leading the way to reduce this wasteful reliance on plastic items across the sector. Its new cardboard Eco Repair Box offers a sustainable alternative to traditional plastic padded envelopes which means that the equipment repair process is much more sustainable.

The family-owned business has also launched an extensive eco range of everyday consumables, including recycled hand towels made from recycled TetraPak cartons, biodegradable nitrile gloves and paper cups

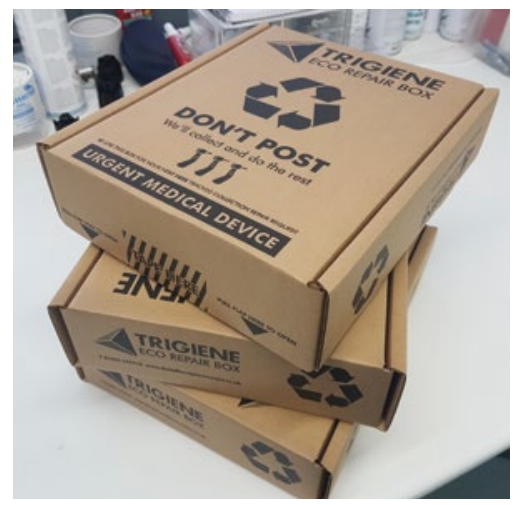

with waterproof natural starch lining. This is just the start of a vast range of eco products that will help dental practices further reduce their impact on the environment.

Trigiene Dental is an authorised independent distributor for major brands including Bien-Air, NSK, W\&H, MK Dent, Densply Sirona and Anthogyr. Trigiene is also committed to delivering the fastest and most secure handpiece repair service available, with a 24-hour turnaround.

To find out more about Trigiene Dental visit: https://www.trigiene.co.uk/.

\section{NEW SECURITY FEATURE FOR PATIENT MANAGEMENT SOFTWARE}

Dentally has now added a new feature to the two factor authentication option within the software, whereby you can download an app to your phone which will give the user a unique one off code to access Dentally - an important update for team members who may be working remotely and away from the dental practice.

Previously two factor authentication was achieved through the receipt of an SMS, but this new extra feature heightens security and means a user no longer has to wait to receive an SMS on their mobile phone. To use this new feature, dental practitioners (and their staff) simply download an authenticator app such as Authy or Google Authenticator, open it for Dentally and it will give a numerical code that the user enters into Dentally in order to complete the login process.

If you would like more information on this or other ways Dentally are working with customers to help them during these challenging times as our society works to prevent the spread of COVID-19, then email hello@dentally.co.
POPULAR WIPES HAVE HAD A MAKEOVER

As the biggest-selling product of Nuview's Continu range, the 2-in-1 wipes have had a makeover. These wipes are now supplied in smart, pre-printed refill pouches,

replacing the original clear pouches with a sticker label.

Continu 2-in-1 wipes are not only Class IIa CE marked for the cleaning and disinfection of medical devices within surgeries, but are also suitable for general surfaces. They provide fast, effective and long-lasting disinfection, whilst also ensuring surfaces are clean and decontaminated for highest levels of compliance with HTM 01-05.

Order your own Continu 2-in-1 wipes by contacting the friendly team at Nuview.

For more information call Nuview on 01453 872266, email info@nuviewltd.com, visit www.nuview.co or 'like' Nuview on Facebook.

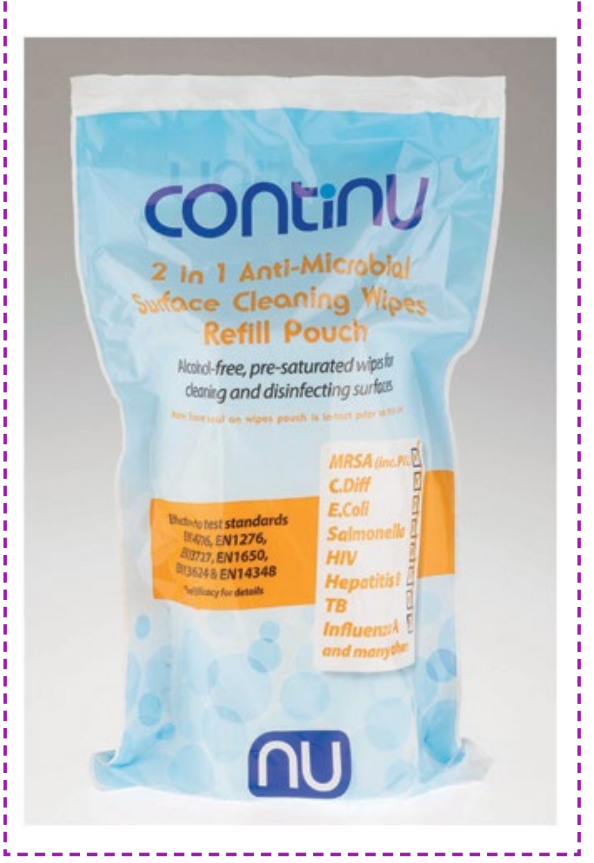

If you would like to promote your products or services direct to the dental industry in BDJ Team, call Andy May on 02078434785 or emaila.may@nature.com 